\title{
Research on the Condition for Balanced Operation of the Single-Phase Induction Motor with Three Parallel-Connected Windings
}

\author{
Liangfeng Guo, Nannan Gao, Ying Pei, Hongbo li, and Kerui Chen
}

\begin{abstract}
In this paper, a novel energy-efficient single-phase induction motor with three parallel-connected stator windings and two external capacitors has been proposed. By selecting the appropriate capacitors, the currents in the three windings will be approximately symmetric at rated load, thus high rated efficiency can be obtained. The condition for balanced operation is analyzed and the method for determining the requested capacitances is also obtained, based on the symmetrical component method. It is concluded that, in comparison with three-phase induction motors of the same capacity, the novel single-phase induction motor has nearly the same efficiency but higher power factor when operating at rated load.
\end{abstract}

Index Terms-The single-phase operation, symmetrical component method, the condition for balanced operation, energy-efficient motor.

\section{INTRODUCTION}

Characterized by simple structure, high reliability as well as easy maintenance, single-phase induction motors, operating on single-phase AC power supply, are widely used in industry, agriculture, transportation and household appliances, etc. However, single-phase service is a problem for customers who need to run large motors for pumping, irrigating, or running heavy machinery, because it is not economic to use single-phase induction motor when the rated power exceeds $0.5 \mathrm{~kW}$. A three-phase induction motor running on a single-phase supply with the help of phase balancers could be an alternative solution. Many researchers have studied this particular case of unbalanced operation for induction motors and a lot of work such as, selection of capacitor for different load, steady state performance, and dynamic performance has been well addressed [1]-[9].

In this paper, a novel energy efficient single-phase induction motor, which has three parallel-connected windings and two capacitors, is proposed. Based on the symmetrical components method, the condition for balanced operation is obtained and the steady-state performances are analyzed.

Manuscript received October 20, 2014; revised March 28, 2015.

The authors are with the State Grid of China Technology College, Jinan, China (email: ggglml@163.com, gao_nannan@163.com, peiyingee@163.com, lihb1176@163.com)

\section{STRUCTURE AND OPERATIONAL PRINCIPLE}

Fig. 1 shows the proposed connection of three-phase induction motor operating on a single-phase supply. There are three symmetrical windings in the stator. The A-phase winding constitutes the first branch. The series connection of capacitor $\mathrm{C}_{1}$ and $\mathrm{B}$-phase winding constitutes the second branch, and the series connection of capacitor $\mathrm{C}_{2}$ and C-phase winding constitutes the third one. The above three branches are connected in parallel as shown in Fig. 1.

It can be seen from Fig. 1 that the current in winding B lags that in winding $\mathrm{A}$, while the current in winding $\mathrm{C}$ leads that in winding $\mathrm{A}$. By an appropriate choice of capacitors $\mathrm{C}_{1}$ and $\mathrm{C}_{2}$, the currents in three-phase windings are approximately balanced at rated load, thus the efficiency of the proposed motor is approximately the same as that of the three-phase induction motors.

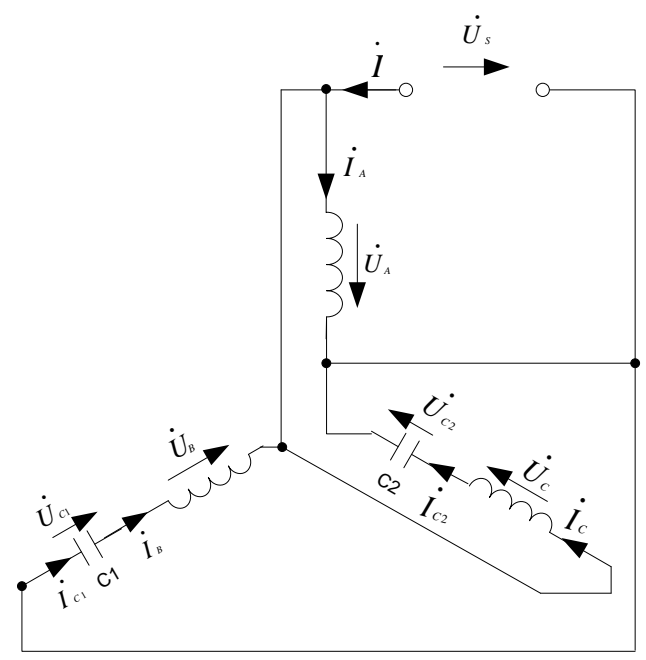

Fig. 1. Connection of the single-phase induction motor with parallel-connected windings.

\section{CONDITION FOR BALANCED OPERATION}

Referring to Fig. 1, the electric circuit equations for the proposed motor can be established. The voltage equations are as follows

$$
\left\{\begin{array}{l}
\dot{U}_{\mathrm{A}}=\dot{U}_{\mathrm{s}} \\
\dot{U}_{\mathrm{B}}+\dot{U}_{C 1}=-\dot{U}_{\mathrm{s}} \\
\dot{U}_{\mathrm{C}}+\dot{U}_{\mathrm{C} 2}=\dot{U}_{\mathrm{s}}
\end{array}\right.
$$

The current equations are 


$$
\left\{\begin{array}{l}
\dot{I}_{C 1}=\dot{I}_{\mathrm{B}} \\
\dot{I}_{C 2}=\dot{I}_{\mathrm{C}}
\end{array}\right.
$$

The equations satisfied by capacitors are

$$
\left\{\begin{array}{l}
\dot{U}_{C 1}=\dot{I}_{C 1} Z_{C 1} \\
\dot{U}_{C 2}=\dot{I}_{C 2} Z_{C 2} \\
Z_{C 1}=R_{C 1}-\mathrm{j} X_{C 1} \\
Z_{C 2}=R_{C 2}-\mathrm{j} X_{C 1}
\end{array}\right.
$$

where $\dot{U}_{\mathrm{s}}$ is the voltage of the single-phase supply, $\dot{U}_{\mathrm{A}}, \dot{U}_{\mathrm{B}}$, and $\dot{U}_{\mathrm{C}}$ the voltages of the three stator windings, respectively, $\dot{I}_{\mathrm{A}}, \dot{I}_{\mathrm{B}}$, and $\dot{I}_{\mathrm{C}}$ are the currents of the three stator windings, respectively, $\dot{U}_{\mathrm{C} 1}$ and $\dot{U}_{\mathrm{C} 2}$ are the terminal voltages of capacitors $\mathrm{C}_{1}$ and $\mathrm{C}_{2}$, respectively, $\dot{I}_{\mathrm{C} 1}$ and $\dot{I}_{\mathrm{C} 2}$ are the currents of the capacitors $C_{1}$ and $C_{2}$, respectively, $Z_{\mathrm{C} 1}$ and $Z_{\mathrm{C} 2}$ are the impedances of the capacitors $\mathrm{C}_{1}$ and $\mathrm{C}_{2}$, respectively, $R_{\mathrm{C} 1}$ and $R_{\mathrm{C} 2}$ are the alternating resistances of the capacitors $\mathrm{C}_{1}$ and $\mathrm{C}_{2}$, respectively, $X_{\mathrm{C} 1}$, and $X_{\mathrm{C} 2}$ are the reactance of the capacitors $\mathrm{C}_{1}$ and $\mathrm{C}_{2}$, respectively.

According to (1), (2), and (3), the phasor diagram for balanced operation can be obtained, as shown in Fig. 2. It can be seen that the input voltage is the same as the phase voltage when balanced operation is achieved. Thus the $380 \mathrm{~V}$ Y-connected three-phase induction motor can be reconnected to be a $220 \mathrm{~V}$ single-phase induction motor directly.

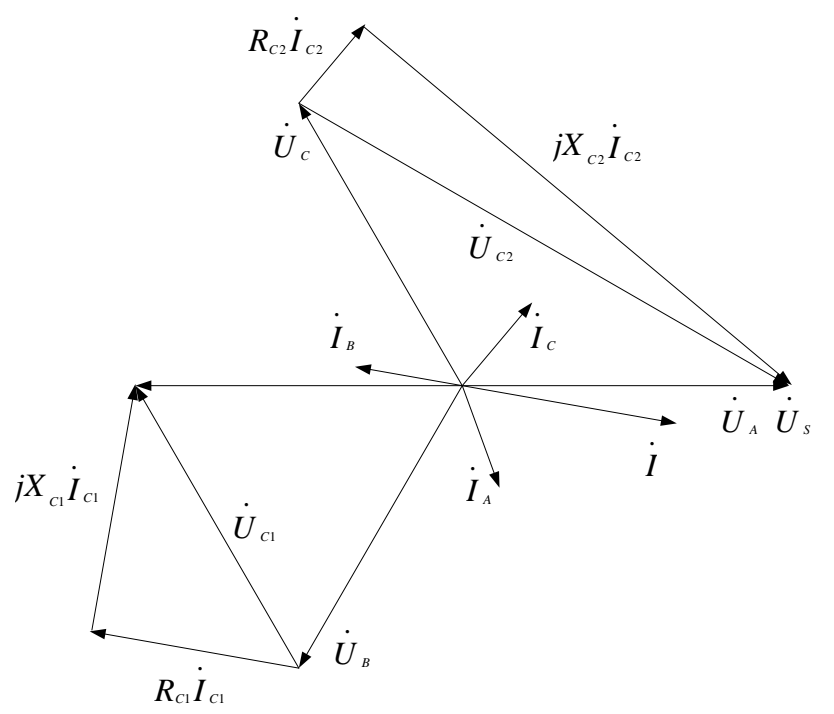

Fig. 2. Phasor diagram for balanced operation.

According to the symmetrical component method, the voltages and currents of the three windings can be expressed as

$$
\left\{\begin{array}{l}
\dot{U}_{\mathrm{A}}=\dot{U}_{+}+\dot{U}_{-}+\dot{U}_{0} \\
\dot{U}_{\mathrm{B}}=a^{2} \dot{U}_{+}+a \dot{U}_{-}+\dot{U}_{0} \\
\dot{U}_{\mathrm{C}}=a \dot{U}_{+}+a^{2} \dot{U}_{-}+\dot{U}_{0}
\end{array}\right.
$$

$$
\left\{\begin{array}{l}
\dot{I}_{\mathrm{A}}=\dot{I}_{+}+\dot{I}_{-}+\dot{I}_{0} \\
\dot{I}_{\mathrm{B}}=a^{2} \dot{I}_{+}+a \dot{I}_{-}+\dot{I}_{0} \\
\dot{I}_{\mathrm{C}}=a \dot{I}_{+}+a^{2} \dot{I}_{-}+\dot{I}_{0}
\end{array}\right.
$$

where $\dot{I}_{+}, \dot{I}_{-}$and $\dot{I}_{0}$ are the positive sequence current, negative sequence current, and zero sequence current, respectively; $\dot{U}_{+}, \dot{U}_{-}$and $\dot{U}_{0}$ are the positive sequence voltage, negative sequence voltage, and zero sequence voltage, respectively; $Z_{+}, Z_{-}$, and $Z_{0}$ are the positive sequence impedance, negative sequence impedance, and zero sequence impedance, respectively. $\alpha=e^{j 120^{\circ}}, \alpha^{2}=e^{-j 120^{\circ}}$.

According to electrical machine theory, the positive sequence impedance $Z_{+}$, negative sequence impedance $Z_{-}$and zero sequence impedance $Z_{0}$ are formulated as follows

$$
\begin{gathered}
Z_{+}=R_{1}+j X_{1 \sigma}+\frac{j X_{\mathrm{m}}\left(\frac{R_{2}^{\prime}}{s}+j X_{2 \sigma}^{\prime}\right)}{\frac{R_{2}^{\prime}}{s}+j\left(X_{2 \sigma}^{\prime}+X_{\mathrm{m}}\right)} \\
Z_{-}=R_{1}+j X_{1 \sigma}+\frac{j X_{\mathrm{m}}\left(\frac{R_{2}^{\prime}}{2-s}+j X_{2 \sigma}^{\prime}\right)}{\frac{R_{2}^{\prime}}{2-s}+j\left(X_{2 \sigma}^{\prime}+X_{\mathrm{m}}\right)} \\
Z_{0}=R_{1}+j X_{1 \sigma}
\end{gathered}
$$

where, $R_{1}$ and $X_{1 \sigma}$ are the resistance and leakage reactance of stator windings, respectively, $X_{\mathrm{m}}$ the magnetizing reactance, $R_{2}^{\prime}$ and $X_{2 \sigma}^{\prime}$ the referred rotor resistance and leakage reactance, respectively, $s$ the slip.

The relations between the sequence voltage and the sequence current are

$$
\left\{\begin{array}{l}
\dot{U}_{+}=\dot{I}_{+} Z_{+} \\
\dot{U}_{-}=\dot{I}_{-} Z_{-} \\
\dot{U}_{0}=\dot{I}_{0} Z_{0}
\end{array}\right.
$$

From (1), (2), (3), (4), (5) and (9), the following equations can be obtained

$$
\left\{\begin{array}{l}
\dot{I}_{+} Z_{+}+\dot{I}_{-} Z_{-}+\dot{I}_{0} Z_{0}=\dot{U}_{s} \\
a^{2}\left(Z_{+}+Z_{C 1}\right) \dot{I}_{+}+a\left(Z_{-}+Z_{C 1}\right) \dot{I}_{-}+\left(Z_{0}+Z_{C 1}\right) \dot{I}_{0}=-\dot{U}_{s} \\
a\left(Z_{+}+Z_{C 2}\right) \dot{I}_{+}+a^{2}\left(Z_{-}+Z_{C 2}\right) \dot{I}_{-}+\left(Z_{0}+Z_{C 2}\right) \dot{I}_{0}=\dot{U}_{s}
\end{array}\right.
$$

Thus,

$$
\dot{I}_{+}=\frac{\left|\begin{array}{ccc}
\dot{U}_{s} & Z_{-} & Z_{0} \\
-\dot{U}_{s} & a\left(Z_{-}+Z_{C 1}\right) & \left(Z_{0}+Z_{C 1}\right) \\
\dot{U}_{s} & a^{2}\left(Z_{-}+Z_{C 2}\right) & \left(Z_{0}+Z_{C 2}\right)
\end{array}\right|}{\Delta}
$$


$\dot{I}_{-}=\frac{\left|\begin{array}{ccc}Z_{+} & \dot{U}_{s} & Z_{0} \\ a^{2}\left(Z_{+}+Z_{C 1}\right) & -\dot{U}_{s} & \left(Z_{0}+Z_{C 1}\right) \\ a\left(Z_{+}+Z_{C 2}\right) & \dot{U}_{s} & \left(Z_{0}+Z_{C 2}\right)\end{array}\right|}{\Delta}$

$$
\dot{I}_{0}=\frac{\left|\begin{array}{ccc}
Z_{+} & Z_{-} & \dot{U}_{s} \\
a^{2}\left(Z_{+}+Z_{C 1}\right) & a\left(Z_{-}+Z_{C 1}\right) & -\dot{U}_{s} \\
a\left(Z_{+}+Z_{C 2}\right) & a^{2}\left(Z_{-}+Z_{C 2}\right) & \dot{U}_{s}
\end{array}\right|}{\Delta}
$$

where

$$
\Delta=\left|\begin{array}{ccc}
Z_{+} & Z_{-} & Z_{0} \\
a^{2}\left(Z_{+}+Z_{C 1}\right) & a\left(Z_{-}+Z_{C 1}\right) & \left(Z_{0}+Z_{C 1}\right) \\
a\left(Z_{+}+Z_{C 2}\right) & a^{2}\left(Z_{-}+Z_{C 2}\right) & \left(Z_{0}+Z_{C 2}\right)
\end{array}\right|
$$

If balanced operation is desired to be achieved, $\dot{I}_{-}=0$ and $\dot{I}_{0}=0$ must be satisfied. Thus the condition for balanced operation can be obtained

$$
\left\{\begin{array}{l}
Z_{C 1}=a^{2} Z_{+} \\
Z_{C 2}=\left(a^{2}-1\right) Z_{+}
\end{array}\right.
$$

It can be seen that the obtained capacitances are corresponding to given speed or load. In other words, when the speed or load changes, the motor will be unbalanced and new capacitances must be used in order to balance the motor.

Fig. 3 shows the positive-sequence equivalent circuit and negative-sequence equivalent circuit of the motor.

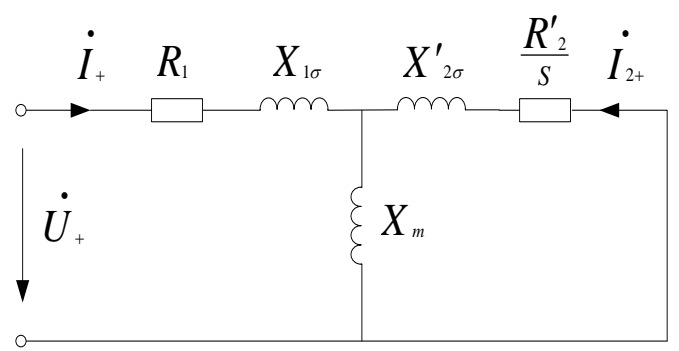

(a) Positive-sequence equivalent circuit

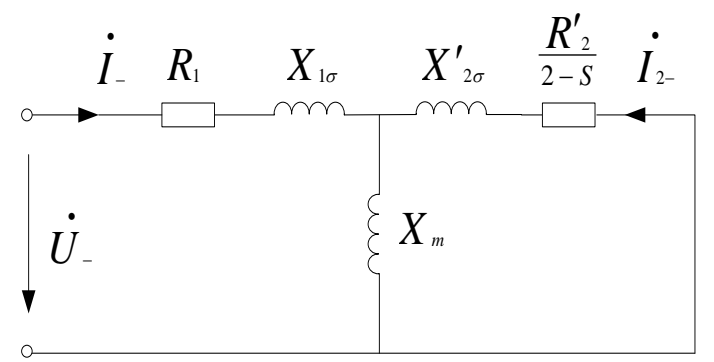

(b) Negative-sequence equivalent circuit

Fig. 3. Equivalent circuit.

The positive-sequence current $\dot{I}_{+}$and the negative-sequence current $\dot{I}_{-}$can be obtained by using the symmetrical component method. Referring to Fig. 3, positive sequence current and negative sequence current in the rotor can be calculated as follows

$$
\left\{\begin{array}{l}
\dot{I}_{2+}=\frac{-j X_{\mathrm{m}}}{\frac{R_{2}^{\prime}}{s}+j\left(X_{2 \sigma}^{\prime}+X_{\mathrm{m}}\right)} \dot{I}_{+} \\
\dot{I}_{2-}=\frac{-j X_{\mathrm{m}}}{\frac{R_{2}^{\prime}}{2-s}+j\left(X_{2 \sigma}^{\prime}+X_{\mathrm{m}}\right)} \dot{I}_{-}
\end{array}\right.
$$

Steady-state Performance Analysis.

\section{Steady State Performance Analysis}

The steady-state performance analysis of the novel energy-efficient single-phase induction motor can be carried out using the symmetrical component method.

The positive sequence electromagnetic power and negative sequence electromagnetic power can be expressed as

$$
\left\{\begin{array}{l}
P_{\mathrm{e}+}=3 I_{2+}^{2} \frac{R_{2}^{\prime}}{S} \\
P_{\mathrm{e}-}=3 I_{2-}^{2} \frac{R_{2}^{\prime}}{2-s}
\end{array}\right.
$$

Thus, the electromagnetic power of the motor can be obtained

$$
P_{\mathrm{e}}=P_{\mathrm{e}+}-P_{\mathrm{e}-}=3 I_{2+}^{2} \frac{R_{2}^{\prime}}{S}-3 I_{2-}^{2} \frac{R_{2}^{\prime}}{2-s}
$$

The positive sequence mechanical power and negative sequence mechanical power can be deduced

$$
\left\{\begin{aligned}
P_{\Omega+} & =P_{\mathrm{e}+}-P_{\mathrm{Cu} 2}=3 I_{2+}^{2} \frac{R_{2}^{\prime}}{s}-3 I_{2+}^{2} R_{2}^{\prime} \\
& =3 I_{2+}^{2} \frac{(1-s) R_{2}^{\prime}}{s}=(1-s) P_{\mathrm{e}+} \\
P_{\Omega-} & =P_{\mathrm{e}-}-P_{\mathrm{Cu} 2}=3 I_{2-}^{2} \frac{R_{2}^{\prime}}{2-s}-3 I_{2+}^{2} R_{2}^{\prime} \\
& =3 I_{2+}^{2} \frac{(s-1) R_{2}^{\prime}}{2-s}=(s-1) P_{\mathrm{e}-}
\end{aligned}\right.
$$

Then, the mechanical power of the motor is

$$
P_{\Omega}=P_{\Omega+}+P_{\Omega-}=(1-s) P_{\mathrm{e}}
$$

The output power can be calculated as follows

$$
P_{2}=P_{\Omega}-P_{0}
$$


where, $P_{0}$ and $P_{\Delta}$ are the mechanical loss and stray loss, respectively.

\section{CONCLUSION}

According to the result of the analysis, both $\mathrm{Z}_{\mathrm{C} 1}$ and $\mathrm{Z}_{\mathrm{C} 2}$ are impedances, i.e. the series connection of resistances and capacitances. The addition of resistance will result in ohmic loss and decrease the efficiency of the motor. To avoid the additional ohmic loss, only capacitors will be connected instead of impedances in Fig. 1. In this case, the motor cannot operate symmetrically. However, by suitable selection of capacitors, the currents in the three windings are approximately balanced at given load.

\section{REFERENCES}

[1] J. E. Brown and C. S. Jha, "The starting of a three-phase induction motor connected to a single phase supply system," Proc. Inst. Elect. Eng., vol. 106, no.1, pp. 183-190, Apr. 1959.

[2] C. E. Tindall and W. Monteith, "Balanced operation of three-phase induction motors connected to single-phase supplies," IEEE Proc., vol. 123, no. 6, pp. 517-522, Jun. 1976

[3] J. H. Alwash, "Predicting performance of three-phase induction motor connected to a single phase supplies," IEEE Proc. B Power, vol. 143, no. 4, pp. 339-344, Jul. 1996.

[4] A. D. Tozune, "Balanced operation of three-phase induction motor with asymmetrical stator windings connected to single-phase supply system," IEEE Proceedings, Part B, vol. 38, no. 4, pp. 167-174, Jul. 1991.

[5] C. H. Salemo, J. R. Camacho, and L. M. Neto, "The asymmetrical three-phase induction motor fed by single phase source comparative performance analysis," IEEE MB, vol. 14, no. 1, pp. 1-3, Jul. 1997.

[6] O. J. M. Smith, "High-efficiency single-phase motors," IEEE Transactions on Energy Conversion, vol. 7, no. 3, pp. 560-569, Sep. 1996.

[7] T. F. Chan and L. Lai, "Steady-state analysis of a three-phase induction motor with Smith connection," IEEE Power Eng. Rev., vol. 20, no. 1, pp. 45-46, Oct. 2000

[8] D. Fu, X. Wang, P. Ji, and R. Tang, "Experimental research of a novel efficient single-phase induction motor," in Proc. the Electrical Machines and Systems, ICEMS 2003, Sixth International Conference on, 2003, vol. 1, pp. 1-3.

[9] X. Wang, H. Zhong, Y. Yang, and X. Mu, "Study of a novel energy efficient single-phase induction motor with three series-connected windings and two capacitors," IEEE Transactions on Energy Conversion, vol. 25, no. 2, pp. 433-440, Jun. 2010.

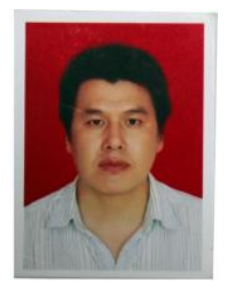

Guo Liangfeng was born in 1978, and obtained the bachelor degree in electrical engineering. Now, he is engaged in training and teaching work about the electrical motor and electrical tests. 